\title{
Controle da leptospirose em bovinos de leite com vacina autógena em Santo Antônio do Monte, Minas Gerais ${ }^{1}$
}

\author{
Denise Chiareli ${ }^{2 *}$, Maria R.V. Cosate ${ }^{2}$, Elvio C. Moreira ${ }^{2}$, Rômulo C. Leite ${ }^{2}$, Francisco \\ C.F. Lobato ${ }^{2}$, José A. da Silva ${ }^{2}$, Juliana F.B. Teixeira ${ }^{2}$ e Andreza P. Marcelino ${ }^{3}$
}

\begin{abstract}
Chiareli D., Cosate M.R.V., Moreira E.C., Leite R.C., Lobato F.C.F., Silva J.A., Teixeira J.F.B. \& Marcelino A.P. 2012. [Control of leptospirosis in dairy cattle with autogenous vaccine in Santo Antônio do Monte, MG, Brazil.] Controle da leptospirose em bovinos de leite com vacina autóctone em Santo Antônio do Monte, Minas Gerais. Pesquisa Veterinária Brasileira 32(7):633-639. Departamento de Medicina Veterinária Preventiva, Escola de Veterinária, Universidade Federal de Minas Gerais, Av. Antônio Carlos 6627, Cx. Postal 567, Belo Horizonte, MG 30123-970, Brazil. E-mail: dchiareli@yahoo.com.br

An outbreak of leptospirosis in dairy cattle was observed in Santo Antonio do Monte, Minas Gerais. The herd had positive reactions in anti-Leptospira serovar Hardjo agglutination test (MAT) and had been previously vaccinated with a vaccine containing serovars Hardjo. The MAT showed $48.06 \%$ of cattle positive for serovars Hardjo genotype Hardjobovis, $36.82 \%$ for serovars Hardjo genotype Hardjoprajitno. The animals had abortions and mastitis with blood in the milk. This study aimed to isolate the existing serovars from the urine of serologically positive cows, produce an experimental vaccine with the serovars isolated in the herd, evaluating the effectiveness of the vaccination program for a period of two years through the herd serology. Leptospira spp. was isolated from the urine of two cows with signs suggestive of the disease. The strains were identified by serology with monoclonal antibodies and $16 \mathrm{~S}$ rRNA gene sequencing as belonging to the Leptospira interrogans species Sejroe serogroup Hardjo serovars and Hardjoprajitno genotype. Use of the autochthonous vaccine was effective in leptospirosis controlling in the herd in two years. The serology results showed the absence of positive animals in the last race held in the herd.
\end{abstract}

INDEX TERMS: Leptospira, Hardjo, leptospirosis, cattle, autogenous vaccine, isolation.

RESUMO.- Um surto de leptospirose foi observado em bovinos leiteiros em Santo Antônio do Monte, Minas Gerais. 0 rebanho apresentava reações positivas anti-leptospira sorovar Hardjo no teste de microaglutinação (MAT) e havia sido vacinado anteriormente com vacina experimental contendo a sorovariedade Hardjo. O MAT revelou $48,06 \%$ dos bovinos positivos para sorovariedade Hardjo genótipo Hardjobovis, 36,82\% para sorovariedade Hardjo genótipo Hardjoprajitno. Os animais apresentavam aborto e mastite com presença de sangue no leite. A pre-

\footnotetext{
${ }^{1}$ Recebido em 7 de setembro de 2011.

Aceito para publicação em 14 de fevereiro de 2012.

${ }^{2}$ Departamento de Medicina Veterinária Preventiva, Escola de Veterinária, Universidade Federal de Minas Gerais (UFMG), Av. Antônio Carlos 6627, Cx. Postal 567, Belo Horizonte, MG 30123-970, Brasil. *Autor para correspondência: dchiareli@yahoo.com.br

${ }^{3}$ Fundação Ezequiel Dias (Funed), Rua Conde Pereira Carneiro 80, Gameleira, Belo Horizonte, MG 30510-010.
}

sente pesquisa teve como objetivos isolar as sorovariedades existentes a partir da urina de vacas sorologicamente positivas, elaborar uma vacina experimental com as sorovariedades isoladas no rebanho, avaliar a eficiência do programa de vacinação por um período de dois anos por meio da sorologia do rebanho. Foi isolada Leptospira spp. a partir da urina de duas vacas com sinais sugestivos da doença. As amostras isoladas foram identificadas pela sorologia com anticorpos monoclonais e seqüenciamento do gene $16 \mathrm{~S}$ rRNA como pertencentes à espécie Leptospira interrogans, sorogrupo Sejroe, sorovariedade Hardjo e genótipo Hardjoprajitno. 0 uso da vacina autógena foi eficaz no controle da leptospirose no rebanho no período de dois anos. Os resultados da sorologia revelaram ausência de animais positivos na última prova realizada no rebanho.

TERMOS DE INDEXAÇÃO: Leptospira, Hardjo, leptospirose, bovino, vacina autógena, isolamento. 


\section{INTRODUÇÃo}

As leptospiroses são zoonoses cosmopolitas que atingem os animais domésticos, silvestres, sinantrópicos e acidentalmente os seres humanos. São enfermidades bacterianas infecto-contagiosas que afetam a saúde animal e possuem grande importância em saúde pública.

No setor pecuário as leptospiroses são responsáveis por perdas econômicas expressivas. Nos bovinos influenciam negativamente o potencial reprodutivo e produtivo, causando aborto, natimortos, nascimento de animais debilitados e infertilidade. Pode ocorrer mastite clínica ou subclínica, com alterações nas características macroscópicas do leite, com estrias de sangue, ocasionando redução na produção de leite do rebanho (Higgins et al. 1980, Ellis 1994).

A sorovariedade Hardjo é a mais adaptada à espécie bovina. Estudos soro-epidemiológicos realizados no Brasil indicaram que essa sorovariedade está amplamente distribuída em praticamente todos Estados do país (Pellegrin et al. 1999, Langoni et al. 2000, Homem et al. 2001, Oliveira \& Pires Neto 2004, Araújo et al. 2005). Entretanto, o seu isolamento foi descrito apenas por Moreira (1994), em bovinos leiteiros em Minas Gerais.

Bovinos são considerados hospedeiros de manutenção da sorovariedade Hardjo, pois possuem elevada suscetibilidade à infecção, a transmissão é endêmica entre os animais dessa espécie, apresentando a doença na forma crônica, caracterizada por problemas reprodutivos. Essa sorovariedade possui dois genótipos: Hardjobovis e Hardjoprajitno. 0 genótipo Hardjobovis pertence à espécie Leptospira borgpetersenii e o genótipo Hardjoprajitno à espécie L. interrogans. Ambos são importantes causadoras de problemas reprodutivos nos rebanhos bovinos do mundo e possuem diferenças nas suas manifestações clínicas. A infecção causada pela Hardjobovis é amplamente encontrada em bovinos de diversos países do mundo e é frequentemente caracterizada pela forma subclínica, ocasionando aborto, enquanto que a hardjoprajitno, isolada em poucos países, caracteriza-se por ser mais patogênica levando a queda da produção de leite e também problemas reprodutivos (Ellis 1994).

O diagnóstico preciso da infecção por leptospira em bovinos depende do isolamento e tipificação da sorovariedade prevalente. No entanto, na maioria dos trabalhos publicados no Brasil, são realizados apenas inquéritos sorológicos que não incluem o isolamento para a identificação do agente, devido à dificuldade na obtenção de resultados conclusivos. 0 diagnóstico é realizado mediante aplicação da técnica Microaglutinação. Porém este teste apresenta algumas limitações, como não permitir a identificação do genótipo específico, além de gerar reações cruzadas entre espécies do gênero leptospira com características antigênicas similares, impossibilitando o diagnóstico preciso referente ao agente infectante.

A dificuldade para identificação da sorovariedade infectante usando técnicas sorológicas e o alto grau de reações cruzadas entre as sorovariedades pode levar a interpretações incorretas. Essa dúvida faz com que os laboratórios produzam vacinas contendo várias sorovariedades, com o objetivo de atender uma demanda diversificada. Como a resposta imunológica das vacinas anti-leptospira leva a baixos títulos e é específica para cada sorovariedade, o uso dessas vacinas comerciais acaba se tornando uma medida profilática ineficiente (Rodrigues et al. 2011).

A identificação e caracterização de leptospiras_são fundamentais tanto para a obtenção de um diagnóstico preciso, como para a produção de vacinas mais eficazes. A inclusão, nas vacinas, de sorovariedades que realmente estejam infectando os rebanhos, poderá induzir uma imunidade mais eficiente e duradoura, que refletirão consequentemente, no controle da doença e melhoramento nos índices reprodutivos e de produtividade animal.

Em uma fazenda leiteira no município de Santo Antônio do Monte, Minas Gerais, foram encontrados animais positivos frente a aglutininas anti-sorovar Hardjo que já haviam sido imunizados com vacina experimental elaborada com a sorovariedade Hardjo genótipo Hardjoprajitno. Verificou-se nessa propriedade que mesmo após implementação do programa de vacinação, os animais apresentaram aumento significativo nos casos de abortos, nascimento de bezerros fracos, mastite com presença de sangue no leite e queda na produção leiteira.

Como a vacina experimental não promoveu o controle da doença no rebanho, o presente trabalho investigou esse foco de infecção por leptospira em bovinos leiteiros na Fazenda Esperança, no município de Santo Antônio do Monte - Minas Gerais, durante o período de 2007-2010, e os objetivos desta pesquisa foram: isolar as sorovariedades existentes a partir da urina de vacas sorologicamente positivas, elaborar uma vacina experimental com as sorovariedades isoladas no rebanho, avaliar a eficiência do programa de vacinação por um período de dois anos por meio da sorologia do rebanho.

\section{MATERIAL E MÉTODOS}

\section{Caracterização do local de estudo}

O experimento foi realizado na Fazenda Esperança, localizada no município de Santo Antônio do Monte, situado na região Oeste de Minas Gerais. A fazenda possui uma área total de 150 hectares, com 75 hectares de área de pastagem. As finalidades de produção pecuária são cria e recria e o sistema de produção de leite é semi-intensivo. 0 processo de retirada do leite é realizado por ordenha mecânica.

No início da pesquisa, o rebanho era constituído por 263 bovinos de aptidão leiteira, da raça Holandesa e animais mestiços (Holandês x Zebu), compondo 61 bezerras, 70 novilhas, 130 vacas e dois touros. 0 método reprodutivo utilizado é inseminação artificial com repasse de touros.

\section{Pesquisa e isolamento de leptospiras}

Foram coletadas 20 amostras de urina de fêmeas positivas pelo Teste de Microaglutinação (MAT) frente à sorovariedade Hardjo e com histórico de problemas reprodutivos. Inicialmente, a região do períneo foi limpa e as amostras de urina foram obtidas após massagem, desprezando-se o jato inicial. A coleta foi realizada com frasco esterilizado de $50 \mathrm{ml}$.

Após a coleta, as amostras de urina foram examinadas por meio de microscopia direta com microscópio Carl Zeiss ${ }^{\circledR}$ em objetiva 40x, ocular 10x e condensador de campo escuro e seco.

Para o isolamento de leptospiras, foi estruturado um laboratório na propriedade para processamento das amostras de urina. 0 
material utilizado para o isolamento foi previamente esterilizado e o local de trabalho foi limpo e higienizado. A urina coletada foi imediatamente diluída a 1:10 em solução salina estéril, pH 7,2. Posteriormente, inoculou-se $0,5 \mathrm{ml}$ desta diluição em duas séries de cinco tubos cada, contendo meios Fletcher e EMJH (Ellinghausen \& McCulloug 1965) modificados com albumina bovina (Faine et al. 1999). As culturas foram transportadas para o Laboratório de Leptospirose do Departamento de Medicina Veterinária Preventiva (DMVP), Universidade Federal de Minas Gerais (UFMG), em temperatura ambiente por aproximadamente duas horas. Posteriormente, no laboratório, os tubos foram incubados em estufa bacteriológica a $28^{\circ} \mathrm{C}$ e observou-se semanalmente, em microscópio de campo escuro, se houve crescimento de leptospiras. As culturas foram examinadas por um período de 16 semanas. Foi considerada positiva a cultura que apresentasse células com morfologia e movimentação compatíveis com Leptospira spp. Os tubos nos quais foram observados crescimento de leptospiras foram submetidos à descontaminação por meio de técnicas de diluição e filtração (Faine et al. 1999). Após o isolamento, a manutenção foi realizada por repetidas sub-culturas em meio EMJH.

\section{Identificação do isolado: espécies e sorovariedades de Lep- tospira spp.}

Para a análise do DNA genômico foram utilizadas neste trabalho as sorovariedades de referência Lai, Ceopenhageni, Hardjo (genótipo Hardjoprajitno - cepa OMS) e Hardjo (genótipo Hardjoprajitno - cepa CTG), classificadas na espécie L. interrogans, Hardjo (genótipo Hardjobovis), classificada na espécie L. borgpetersenii e os isolados Lagoa e Bolívia. As leptospiras foram cultivadas em meio EMJH, a $28^{\circ} \mathrm{C}$ em estufa bacteriológica.

\section{Isolamento do DNA}

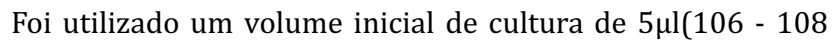
de bactérias), foram centrifugadas a $13000 \mathrm{~g}$ na preparação de obtenção do DNA. As bactérias foram incubadas overnight a $50^{\circ} \mathrm{C}$ com $200 \mu \mathrm{l}$ de solução de lise, contendo $50 \mathrm{mM}$ Tris- $\mathrm{HCl}$, pH8,0, $50 \mathrm{mM}$ EDTA, $100 \mathrm{mM} \mathrm{NaCl}, 1 \%$ SDS, contendo $100 \mu \mathrm{g}$ de proteinase K. A extração do DNA foi realizada com fenol/clorofórmio e a precipitação foi realizada com etanol (Tamai et al. 1988).

\section{PCR- específica}

A PCR específica foi realizada com os iniciadores 16SF: 5'- GAACGGGTGAGTAAC- 3' e 16SR: 5'- ATCGTCGCCTTGGTG- 3'. A amplificação foi realizada em volume total de $10 \mu \mathrm{l}$, contendo $5 \mu \mathrm{g}$ de DNA genômico, 1,5mM MgCl2, $200 \mu \mathrm{M}$ de cada DNTP, 0,4IU Taq DNA Polimerase (Invitrogen) e 1 pmol de cada iniciador em $10 \mathrm{mM}$ Tris $/ \mathrm{HCl}(\mathrm{pH} 8,0), 50 \mathrm{mM} \mathrm{KCl}$. Após a desnaturação inicial de $94^{\circ} \mathrm{C}$ por 3 min., a PCR específica foi realizada em 30 ciclos de $94^{\circ} \mathrm{C}$ por 30 seg., $51^{\circ} \mathrm{C}$ por 1 min e $72^{\circ} \mathrm{C}$ por 1 min. 0 último ciclo constituiu de extensão a $72^{\circ} \mathrm{C}$ por $3 \mathrm{~min}$. Os produtos da PCR foram analisados em gel de agarose $1 \%$ e corados em brometo de etídeo.

\section{Sequenciamento dos produtos de PCR}

$O$ seqüenciamento de fragmentos amplificados com os iniciadores 16S rRNA ribossomal a partir do DNA genômico foi realizado no seqüenciador 7500 (Applied Biosystem) de acordo com as instruções do fabricante. Foram utilizados 100ng do DNA analisado, iniciadores a $10 \mathrm{pmol}$ (16SF ou $16 \mathrm{SR}$ ), com um volume final de reação de $10 \mu$ l. As sequências nucleotídicas obtidas foram analisadas no programa NCBI (National Center of Biotechnology Information), utilizando o algoritmo Blast.

\section{Identificação fenotípica}

A identificação fenotípica dos isolados foi realizada pelo MAT com uso de anticorpos monoclonais (mAbs). Os mAbs foram sele- cionados de acordo com as sorovariedades já isoladas em Minas Gerais em bovinos, Hardjo e Mini (Moreira, 1994). A aquisição dos mAbs foi realizada no Laboratório de referência Royal Tropical Institute, Amsterdã, que indicaram as amostras F16C28 e F106C9, que aglutinam as sorovariedades Hardjo e Mini respectivamente. O mAb F16C28 é capaz de diferenciar os genótipos Hadjobovis e Hardjoprajitno, pois os títulos de aglutinação das duas são diferentes. Hardjobovis aglutina com título de 1:2560 e Hardjoprajitno aglutina com título de 1:80 a 1:640. 0 título de aglutinação da sorovariedade mini com o mAb F106C9 é 1:1280. As sorovariedades de referência utilizadas na prova foram: Hardjoprajitno (OMS), Hardjobovis, Mini, Wolffi e Sejroe.

\section{Prova sorológica}

As amostras de Leptospira spp. foram utilizadas como antígenos na prova sorológica foram: Icterohaemorrhagiae, Pomona, Hardjoprajitno (OMS), Hardjoprajitno (Norma), Hardjobovis, Mini e Gryppothyphosa.

As culturas foram mantidas e cultivadas em meio EMJH enriquecido com albumina bovina descrito por Faine et al. (1999) e foram utilizadas após sete dias de crescimento.

A pesquisa de aglutininas anti-leptospiras foi realizada utilizando-se a Técnica de Microaglutinação (MAT), descrita por Galton (1965).

Foram considerados positivos os soros diluídos a partir de 1:100 quando no campo microscópico apresentaram no mínimo $50 \%$ ou mais de leptospiras aglutinadas. Os soros positivos foram titulados por diluições geométricas de razão dois, considerando-se título positivo a maior diluição com $50 \%$ ou mais de_leptospiras aglutinadas.

\section{Preparação da vacina}

Foi produzida uma bacterina com as amostras isoladas na propriedade. As amostras isoladas foram cultivadas por um período de 14 dias a $28^{\circ} \mathrm{C}$ em meio EMJH enriquecido com albumina bovina conforme descrito por Faine et al. (1999). O crescimento foi monitorado semanalmente. Foi considerada positiva a cultura que apresentasse células com morfologia e movimentação compatíveis com Leptospira spp. A contagem de células foi realizada de acordo com descrito por Rodrigues et al. (2011) em câmara de Petroff-Hausser. Ao final da segunda semana, a cultura apresentou uma densidade de $1 \times 10^{9}$ células $/ \mathrm{mL}$. As bactérias foram inativadas com formaldeído na concentração final $0,3 \%(\mathrm{~V} / \mathrm{V})$, dividida em três alíquotas de $1000 \mathrm{ml}$. Cada alíquota foi emulsionada em adjuvante de emulsão óleo em água (Emulsigen $®)$ na concentração de $20 \%$ e acrescentado vermelho fenol 0,01\% como indicador de $\mathrm{pH}(7,2)$.

A bacterina foi homogeneizada em homogeneizador circular durante 24 horas com 96 rotações por minuto. A vacina foi avaliada previamente com relação à pureza e inocuidade, conforme normas preconizadas pela OIE (2010).

\section{Esquema de vacinação}

Foram vacinados todos os animais que possuíam idade superior a quatro meses. A dose utilizada em cada bovino foi de $5,0 \mathrm{ml}$, inoculada por via subcutânea na região do terço proximal do pescoço. Os animais receberam duas doses com intervalo de 45 dias e revacinação semestralmente.

\section{Monitoramento do rebanho pós-vacinação}

Foi realizado o acompanhamento semestral do rebanho vacinado por dois anos. Coletou-se sangue para realização da sorologia e urina para a pesquisa de leptospiras por meio de microscopia de campo escuro e isolamento através da cultura. 
Após a implementação do programa de controle com vacina autóctone, foram examinadas 60 amostras de urina. As coletas foram realizadas em 29.3.2008, 25.11.2008, 16.6.2009 e 22.4.2010, em cada uma foram coletadas 15 amostras de urina de animais com problemas reprodutivos. Foi realizada a limpeza da região do períneo e as amostras de urina foram obtidas após massagem desprezando-se o jato inicial. A coleta foi realizada com frasco esterilizado de $50 \mathrm{ml}$.

O sangue foi colhido da veia caudal externa em tubos Vaccutainer ${ }^{\circledR}$ de $10 \mathrm{~mL}$, e foram armazenados em caixas isotérmicas contendo gelo reciclável. As amostras de sangue total foram submetidas à centrifugação a $3.000 \mathrm{rpm}$ por $5 \mathrm{~min}$, e retirado o sobrenadante (soro), identificadas e congeladas a $-20^{\circ} \mathrm{C}$ até o momento da utilização. Foi coletado sangue de todas as novilhas, vacas e touros do rebanho. A variação do tamanho da amostra em cada coleta de sangue ocorreu devido à venda de animais do rebanho.

\section{Aprovação do Comitê de Ética em Pesquisa}

Essa pesquisa foi submetida ao Comitê de Ética em Experimentação Animal (CETEA) na UFMG e foi aprovada em reunião em 10.9.2008 com número de protocolo 163/08.

\section{RESULTADOS}

\section{Isolamento de Leptospira}

Na primeira coleta de urina em animais com sinais clínicos e subclínicos de leptospirose realizada em 13.05.2007, 20 amostras foram submetidas ao exame direto por microscopia de campo escuro. Não foi observado resultado positivo ao exame direto. As amostras foram inoculadas em meio de cultura. Na quarta semana foi observado crescimento bacteriano em duas amostras de urina. As leptospiras isoladas passaram a fazer parte da bateria de antígenos utilizada nos testes sorológicos com a finalidade de se obter uma identificação preliminar do sorogrupo envolvido. As amostras foram identificadas como Lagoa e Bolívia, que eram os nomes das fêmeas nas quais essas amostras foram isoladas.

Após a implementação do programa de controle com vacina autógena, foram realizadas semestralmente quatro coletas de 15 amostras de urina. Não foram observadas amostras de urina positivas ao exame direto por microscopia de campo escuro. Não houve crescimento em cultura nas 60 amostras de urina inoculadas em meio EMJH e Fletcher durante o período estudado.

\section{Caracterização do isolado}

O Sequenciamento parcial do fragmento de $1500 \mathrm{bp}$ referente à região $16 \mathrm{~S}$ rRNA ribossomal de seis cepas classificadas na espécie $L$. interrogans e uma cepa classificada na espécie Leptospira borgpetersenii permitiu identificar polimorfismos pontuais quando se fez a comparação entre as diferentes espécies analisadas, como mostrado na figura 1 . De acordo com os resultados encontrados, o seqüenciamento revelou que os dois isolados pertencem à espécie L. interrogans.

A identificação fenotípica dos isolados, realizada pelo MAT com uso de anticorpos monoclonais (mAbs), indicaram perfis de aglutinação das amostras Bolívia e Lagoa semelhantes ao da amostra de referência Hardjo (OMS), pertencente ao genótipo Hardjoprajitno, o que sugere que os isolados pertencem a sorovariedade Hardjo, genótipo Hardjoprajitno (Tabela 1).

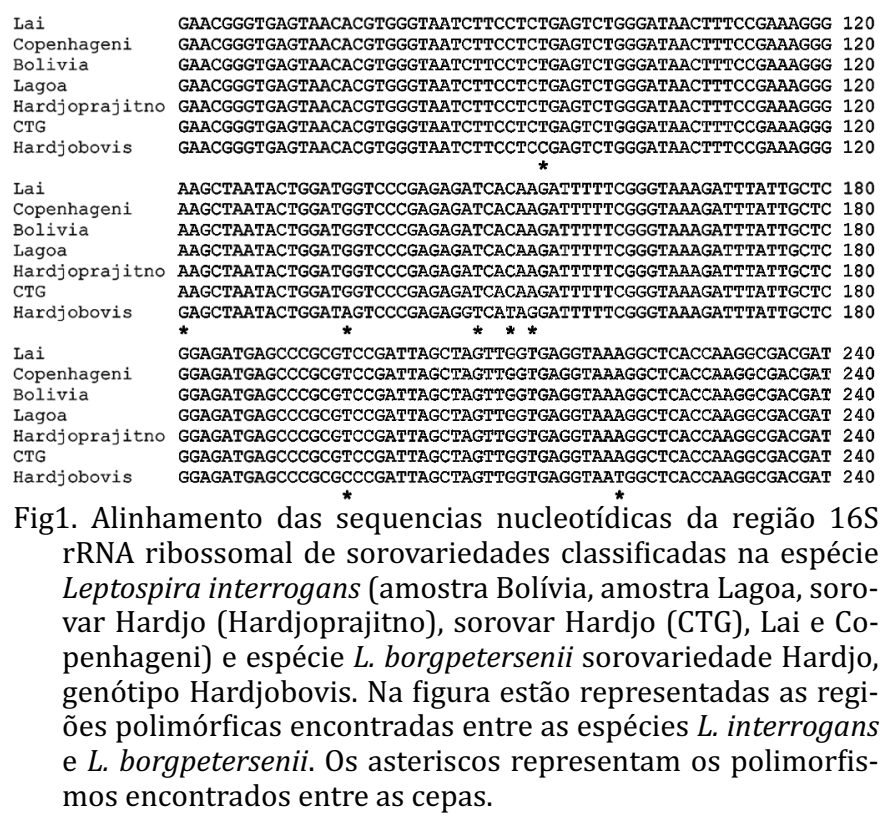

Quadro 1. Títulos de aglutinação de anticorpos monoclonais com sorovariedades de referência e os isolados de Leptospira spp. Bolívia e Lagoa

\begin{tabular}{|c|c|c|c|c|c|c|c|}
\hline mAbs & \multicolumn{5}{|c|}{ Amostras de Referência } & \multicolumn{2}{|c|}{ Amostra Isoladas } \\
\hline Código & Hardjo (OMS) & Hardjobovis & Wolffi & Mini & Serjoe & Lagoa & Bolívia \\
\hline F16C28 & 640 & 2560 & - & - & - & 640 & 640 \\
\hline F106C9 & & 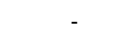 & - & 1280 & - & - & - \\
\hline
\end{tabular}

- Ausência de aglutinação.

\section{Sorologia e vacinação}

A sorologia da primeira coleta de amostras de sangue em todos os bovinos do rebanho, realizada em 13.09.2007, em 258 animais, está representada na Figura 2. Nessa coleta os resultados revelaram altas porcentagens de animais positivos para as sorovariedades Hardjo genótipo Hardjoprajitno e Hardjobovis. Nessa sorologia as amostras de leptospiras isoladas (Lagoa e Bolívia) foram incluídas na prova sorológica e apresentaram diferenças em suas porcentagens de reações. Dos 258 soros, 124 (48,06\%) es-

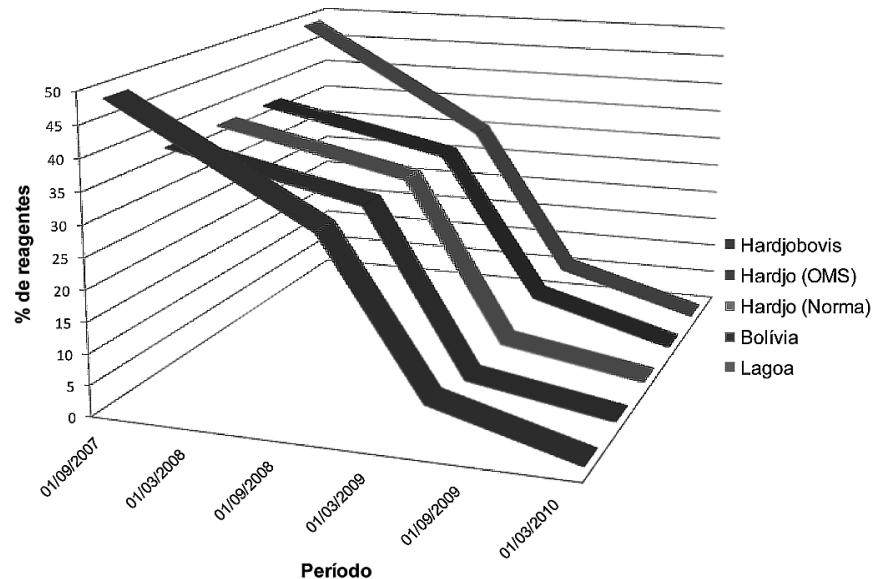

Fig.2. Evolução cronológica do percentual de bovinos positivos frente às sorovariedades Hardjo e amostras Bolívia e Lagoa, no período de 13.9.2007 a 22.4.2010. Fazenda Esperança, Santo Antônio do Monte/MG. 
tavam positivos para Hardjobovis, 95 (36,82\%) estavam positivos para Hardjo (Norma), Hardjo (OMS) e o isolado Bolívia e 125 (48,45\%) estavam positivos para a amostra isolada Lagoa.

Na segunda sorologia realiza em 236 soros sanguíneos de bovinos, em 25.11.2008, após cinco meses da primeira vacinação, foram $72(30,51 \%)$ reações positivas para a Hadjobovis e o isolado Lagoa e $71(30,08 \%)$ reações positivas para sorovariedade Hardjo (OMS), Hardjo (Norma) e o isolado Bolívia. Na terceira sorologia realizada em 176 soros sanguíneos de bovinos em 16.06.2009, após seis meses da última vacinação, foram encontradas $15(6,36 \%)$ reações positivas para as amostras Hadjobovis e isolados Lagoa e Bolívia, e $9(3,81 \%)$ reações positivas para sorovariedade Hardjo (OMS), Hardjo (Norma). Na última sorologia realizada em 191 soros sanguíneos de bovinos, em 22.04.2010, após quatro meses da última vacinação, todos os animais testados estavam negativos na sorologia.

A sorologia realizada pela técnica de MAT, após a implementação do programa de vacinação, a partir de março de 2008 , indicou queda gradativa dos percentuais de bovinos soropositivos, que pode ser observada na Figura 2, que representa a evolução cronológica dos percentuais de bovinos positivos para as sorovariedades Hardjobovis, Hardjo (OMS), Hardjo (Norma) e as duas amostras isoladas Bolívia e Lagoa. As sorovariedades Icterohaemorrhagiae, Pomona, Mini e Gryppothyphosa não apresentaram nenhuma reação positiva na prova sorológica em nenhuma das quatro coletas realizadas.

\section{DISCUSSÃO}

No presente estudo, resultados positivos na sorologia com aglutininas anti sorovariedade Hardjo, assim como o isolamento da sorovariedade Hardjo a partir da amostra de urina de duas vacas, que apresentavam histórico de aborto e presença de sangue no leite, confirmaram que, apesar de dois anos do programa de vacinação anteriormente instituído, a doença não havia sido controlada.

De acordo com os registros da propriedade, o rebanho da Fazenda Esperança estava submetido a um programa de vacinação semestral, entretanto os animais vacinados continuavam a apresentar casos de aborto, repetições de cio, natimortos, nascimento de bezerros fracos e queda na produção do leite em abril de 2007.

A técnica de MAT foi utilizada para identificação prévia das duas amostras isoladas e para acompanhamento sorológico do rebanho após a implantação de novo esquema de vacinação. Em dois anos de investigação, nos resultados obtidos em mais de 200 reações sorológicas positivas, as amostras isoladas, que foram denominadas Bolívia e Lagoa, tinham reações cruzadas com as sorovariedades Hardjo genótipos Hardjobovis e Hardjoprajitno. Esses resultados sugerem que os isolados pertencem ao sorogrupo Sejroe e a sorovariedade Hardjo.

0 seqüenciamento do gene $16 \mathrm{~S}$ rRNA tem sido utilizada como uma ferramenta de tipificação de isolados, certificação de painéis de leptospira, e aplicações taxonômicas (Morey et al. 2006; Perolat et al. 1994). A região 16S rRNA ribossomal em bactérias corresponde a uma região de identidade bacteriana devido características estruturais conservadas. Na identificação de microorganismos possibilita a classificação de cepas bacterianas ao nível de espécie (Clarridge 2004). 0 sequenciamento parcial da região 16S rRNA ribossomal das sete amostras analizadas revelou homologia entre as espécies classificadas na espécie Leptospira interrogans com as amostras isoladas Lagoa e Bolívia e polimorfismos com a amostra L. borgpetersenii (Hardjobovis). De acordo com os resultados encontrados, o sequenciamento revelou que os dois isolados pertencem à espécie L. interrogans. No gênero leptospira, bactérias classificadas no genótipo Hardjoprajitno pertencem à espécie L. interrogans, enquanto o genótipo Hardjobovis pertence à espécie $L$. borgpetersenii. Consequentemente, com os resultados fornecidos pelo seqüenciamento e a identificação fenotípica pelo MAT com uso de anticorpos monoclonais, as amostras isoladas Lagoa e Bolívia pertencem à espécie L. interrogans, sorogrupo Sejroe, sorovariedade Hardjo e genótipo Hardjoprajitno.

No Brasil a leptospirose é endêmica em bovinos, e já foi detectada por inúmeros pesquisadores em praticamente todas as regiões do país (Pellegrin et al. 1999, Langoni et al. 2000, Homem et al. 2001, Oliveira \& Pires Neto 2004, Araújo et al. 2005). Nestes estudos soroepidemiológicos a sorovariedade Hardjo tem se apresentado como a mais freqüente.

Em Minas Gerais, a hipótese da existência da sorovariedade Hardjo infectando os bovinos foi investigada e posteriormente foi confirmada com o primeiro isolamento e tipificação da Hardjo, genótipo Hardjoprajitno, no país (Moreira 1994). Confirmando a hipótese do pesquisador de que essa sorovariedade seria a principal leptospira responsável por problemas reprodutivos em bovinos no Brasil.

A vacinação tem sido descrita como a melhor ferramenta disponível para o controle da leptospirose em bovinos, pois reduz a ocorrência da infecção e os problemas reprodutivos relacionados à hardjo (Dhaliwal et al. 1996). Entretanto, não é possível a proteção adequada de um rebanho se as amostras predominantes na espécie bovina não estiverem incluídas (Bolin et al. 1989).

Na presente investigação, a bacterina contendo as amostras de leptospira isoladas na propriedade foi eficaz no controle da leptospirose em rebanho leiteiro. Nos bovinos, o principal mecanismo de transmissão da sorovariedade Hardjo é a direta, isto é bovino-bovino (Ellis et al. 1981, Ribeiro 1988). Provavelmente houve um bloqueio nesse mecanismo de transmissão, permitindo o controle da doença.

Para o controle da doença no rebanho com o programa de vacinação utilizado, foram necessários 25 meses para que houvesse $100 \%$ de resultados negativos na prova sorológica. Resultado muito semelhante foi encontrado por Moreira (1994).

A partir da implantação do programa de vacinação, observou-se a diminuição dos casos de aborto e mastites, havendo queda gradativa do percentual de bovinos positivos na sorologia, revelando tendência decrescente chegando resultados totalmente negativos em 22.4.2010.

No rebanho estudado, a aquisição de novilhas e reprodutoras, foi possivelmente um fator importante na introdução da leptospirose no rebanho. Bennett (1993) citou tam- 
bém outros fatores de riscos como: pastagem simultânea com bovinos infectados, o uso de touros infectados em coberturas naturais e acesso de bovinos a água contaminada, como riachos, rios ou água de drenagem.

As vacinas anti-Leptospira conferem principalmente uma proteção por anticorpos da classe IgG que atuam nos epítopos presentes no envelope externo do microrganismo. De acordo com Dhaliwal et al. (1996) a melhora nos índices reprodutivos do rebanho após a vacinação, fato esse também observado neste trabalho, pode ser resultado da transudação da IgG no útero, resultando na eliminação da infecção uterina.

As vacinas anti-leptospira produzidas com antígeno inativado são imunógenos fracos, gerando resposta imune apenas do tipo humoral, em muitas ocasiões com baixo título de anticorpos e que persistem por um curto período de tempo (Bolin et al. 1989, Arduino et al. 2009). Em estudo recente avaliou-se bacterinas polivalentes produzidas comercialmente para bovinos e uma vacina monovalente produzida com a sorovariedade Hardjo. Foram encontrados resultados superiores de tempo de duração de títulos de anticorpos protetores para a vacina monovalente. Enquanto as bacterinas polivalentes exigem no mínimo revacinações a cada quatro meses a bacterina monovalente exige revacinações a cada seis meses (Rodrigues et al. 2011).

As vacinas elaboradas com sorovariedades mais prevalentes do local ou com amostras autóctones como a elaborada neste estudo, provavelmente produzem resposta imunológica superior quando comparada às vacinas polivalentes normalmente produzidas para uso comercial. Fato que coincidem com observado no estudo de Bolin \& Alt (2001), no qual uma vacina monovalente com genótipo Hardjobovis protegeu o gado da colonização renal e leptospiúria por quatro meses após a vacinação.

0 mais indicado na elaboração para as vacinas anti-leptospira seria a formulação com o menor número possível de sorovariedades, dando-se especial ênfase para aquelas que realmente estejam presentes na região (Moreira 2004, Araujo et al. 2005). Nas vacinas anti-leptospira comerciais são incluídas várias sorovariedades que não possuem importância epidemiológica para espécie bovina, o que poderia estar levando a uma vacinação ineficaz (Rodrigues et al. 2011).

\section{CONCLUSÕES}

As amostras de leptospiras isoladas Lagoa e Bolívia pertencem à espécie Leptospira interrogans, sorogrupo Sejroe, sorovariedade Hardjo e genótipo Hardjoprajitno.

A vacina experimental elaborada com as amostras autóctones foi eficiente no controle da leptospirose no rebanho bovino.

A sorologia do rebanho bovino realizada pela Técnica de Microaglutinação (MAT) permitiu avaliar a evolução do controle e da ocorrência de novas infecções por leptospira no rebanho.

Agradecimentos.- D. Chiareli foi bolsista da Coordenação de Aperfeiçoamento de Pessoal de Nível Superior (CAPES). E.C. Moreira, M.R.V. Cosate e o laboratorista Antônio Beijamin de Paula foram bolsistas do Conselho Nacional de Desenvolvimento Científico e Tecnológico (CNPq).

\section{REFERÊNCIAS}

Araujo V.E.M., Moreira E.C., Naveda L.A.B., Silva J.A. \& Contreras R.L. 2005. Freqüência de aglutininas anti-Leptospira interrogans em soros sangüíneos de bovinos, em Minas Gerais, de 1980 a 2002. Arq. Bras. Med. Vet. Zootec. 57(4):430-435.

Arduino G.G.C., Girio R.J.S., Magajevski F.S. \& Pereira G.T. 2009. Títulos de anticorpos aglutinantes induzidos por vacinas comerciais contra leptospirose bovina. Pesq. Vet. Bras. 29(7):575-582.

Bennett R.M. 1993. Decision support models of leptospirosis in dairy herds. Vet. Rec. 132(3):59-61.

Bolin C.A., Thiermann A.B., Handsaker A.L. \& Foley J.W. 1989. Effect of vaccination with a pentavalent leptospiral vaccine on Leptospira interrogans serovar hardjo type hardjo-bovis infection on pregnant cattle. Am. J. Vet. Res. 50(1):161-165.

Bolin C.A. \& Alt D.P. 2001. Use of a monovalent leptospiral vaccine to prevent renal colonization and urinary shedding in cattle exposed to Leptospira borgpetersenii serovar Hardjo. Am. J. Vet. Res. 62(7):995-1000.

Censo Agropecuário 2006. Efetivo/rebanho, Brasil, MG. IBGE, [s.l. Disponível em <http://www.ibge.gov.br.html> Acesso em 6 abr. 2009.

Clarridge J.E. 2004. Impact of $16 \mathrm{~S}$ rRNA gene sequence analysis for identification of bacteria on clinical microbiology and infectious diseases. Clin. Microbiol. Rev. 17 (4):840-862.

Dhaliwal G.S., Murray R.D., Dobson H., Montgomery H.J. \& Ellis W.A. 1996. Effect of vaccination against Leptospira interrogans serovar hardjo on milk production and fertility in dairy cattle. Vet. Rec. 138(14):334-335.

Ellinghausen H.C. \& McCullough W.G. 1965. Nutrition of Leptospira pomona and growth of 13 other serotypes: fractionation of oleic albumin complex and a medium of bovine albumin and polysorbate 80 . Am. J. Vet. Res. 26:45-51.

Ellis W.A., O'Brien J.J. \& Cassells J. 1981. Role of cattle in the maintenance of Leptospira interrogans serotype hardjo infection in North Ireland. Vet. Rec. 108:555-557.

Ellis W.A. 1994. Leptospirosis as a cause of reproductive failure. Vet. Clin. North Am., Food Anim. Pract. 10(3):463-478.

Faine S., Adler B., Bolin C. \& Perolat P. 1999. Leptospira and Leptospirosis. $2^{\text {nd }}$ ed. Medi Science, Melbourne. 272p.

Galton M.M., Sulzer C.R., Santa Rosa C.A. \& Fields M.J. 1965. Application of a microtechnique to the agglutination test for leptospiral antibodies. Appl. Microbiol., 13(1):81-85.

Higgins R.J., Harbourne J.F. \& Little T.W.A. 1980. Mastitis and abortionin dairy cattle associated with Leptospira of the serotype hardjo. Vet. Rec. 107:307-310.

Homem V.S.F., Heinemann M.B., Morais Z.M., Vasconcellos S.A., Ferreira F. \& Ferreira Neto J.S. 2001. Estudo epidemiológico da leptospirose bovina e humana na Amazônia Oriental brasileira. Revta Soc. Bras. Med. Trop. 34(2):173-180.

Langoni H., Meireles L.R., Gottschalk S., Cabral K.G. \& da Silva A.V. 2000. Perfil sorológico da leptospirose bovina em regiões do Estado de São Paulo. Arqs Inst. Biológico, São Paulo, 67:37-41.

Moreira E.C. 1994. Avaliação de métodos para erradicação de leptospiroses em bovinos leiteiros. Minas Gerais, Brasil. Tese de Doutorado em Medicina Veterinária Preventiva, Escola de Veterinária, Universidade Federal de Minas Gerais, Belo Horizonte. 94p.

Moreira E.C. 2004. Leptospirose: difícil erradicação. Cultivar Bov. 10:25-28.

Morey R.E., Galloway R.L., Bragg S.l., Steigerwalt A.G., Mayer L.W. \& Levett P.N. 2006. Species-Specific Identification of Leptospiraceae by $16 \mathrm{~S}$ rRNA Gene Sequencing. J. Clin. Microbiol. 44(10):3510-3516.

OIE 2010. Manual of Diagnostic Tests and Vaccines for Terrestrial Animals. Chapter 2.1.9. Leptospirosis. Disponível em http://www.oie.int/ en/international-standard-setting/terrestrial-manual/access-online/ Acessado em 6 fev. 2011.

Oliveira S.J. \& Pires Neto J.A.S. 2004. Aspectos etiológicos e diagnóstico nas leptospiroses. Revta CFMV 10(33).

Pellegrin A.O., Guimarães P.H.S., Sereno J.R.B., Figueiredo J.P., Lage A.P., 
Moreira E.C. \& Leite R.C. 1999. Prevalência da Leptospirose em Bovinos no Pantanal Mato-grossense. Comum. Téc. 22, Embrapa Pantanal, Corumbá. 10p.

Perolat P., Merien F., Ellis W.A. \& Baranton G. 1994. Characterization of Leptospira Isolates from Serovar Hardjo by Ribotyping Arbitrarily Primed PCR, and Mapped Restriction Site Polymorphisms. J. Clin. Microbiol. 32(8):1949-1957.

Ribeiro S.C.R. 1988. Alguns aspectos da infecção por Leptospirra interrrogans, numa fazenda de Minas Gerais, Brasil. Dissertação de Mestrado em Medicina Veterinária, Escola de Veterinária, Universidade Federal de Minas Gerais, Belo Horizonte. 42p.

Rodrigues R.O., Herrmann G.P., Heinemann M.B., Lage A.P., Lopes L.B. \& Moreira E.C. 2011. Comparação entre a imunidade induzida em bovinos vacinados com bacterinas polivalentes comerciais e uma monovalente experimental. Pesq. Vet. Bras. 31(1):10-16.

Tamai T., Sada E. \& Kobayashi Y. 1988. Restriction Endonuclease DNA Analysis of Leptospira interrogans Serovars Icterohaemorrhagiae and Copenhageni. Microbiol. Immunol., 32(9):887-894. 